\title{
Algorithm of Structural Optimization for Digital CMOS Circuits
}

\author{
S.V. Gavrilov, D.I. Ryzhova, N.O. Vasilyev, T.D. Zhukova \\ Institute for Design Problems in Microelectronic of Russian Academy of Sciences (IPPM RAS), \\ Russia, Moscow, Zelenograd \\ sergey_g@ippm.ru, ryzhova_d@ippm.ru, vasilyev_n@ippm.ru
}

\begin{abstract}
In this article we offer area optimization algorithm for digital CMOS circuits that combine two optimization stages. The first one based on the laws of Boolean algebra and reduces circuit area by optimizing Boolean function. The second approach reduces area by removing isolating gates between adjacent transistors. The concept of transistor orientations is used for this purpose. These approaches are performed in an optimization cycle based on a simulated annealing algorithm.
\end{abstract}

Keywords - inter-gate resynthesis, structural optimization, integrated circuit (IC), computer-aided design (CAD), Boolean algebra.

\section{INTRODUCTION}

Modern advances in the development of microelectronic systems are associated with the evolution of computer-aided design tools. An important role in modern CAD systems is played by optimization algorithms for such characteristics as area, power consumption and performance. To achieve the required values for this parameters new more efficient algorithms for structural and parametric optimization are being developed in the automated design route of the IC. Such algorithms generally consist of the following stages: logical optimization of a system of Boolean functions [1], circuit's optimization [5] and layout optimization.

The proposed optimization approach consists of two related stages, which are alternately performed in an optimization cycle. At the first stage, optimization of Boolean functions and the circuit is performed. This stage is followed by layout optimization.

The rest of the paper is organized as follows. Section II presents a graph model for describing the scheme, taking into account the layout implementation. Section III discusses a structural optimization algorithm based on logical transformations. Section IV describes the layout optimization method. Section V describes the flow of the developed program based on the proposed approach. Results are given in section VI.

\section{GRAPH MODEL}

The proposed approach is based on series-parallel graph model (SP-graph) [1] - [3]. The following functions are used for the logical description of the circuit: a conjunction for a serial connection inside the gate ( $\mathrm{f}(\mathrm{a}, \mathrm{b})$ $=\mathrm{a} \& \mathrm{~b}$ ), a disjunction for a parallel connection inside the gate $(\mathrm{f}(\mathrm{a}, \mathrm{b})=\mathrm{a}+\mathrm{b})$, a negation $(\mathrm{f}(\mathrm{a})=\sim \mathrm{a})$, conjunction with negation for serial connection at the gate output (f (a, b) $=\sim(\mathrm{a} \& \mathrm{~b}))$, disjunction with negation for parallel connection at the gate output $(\mathrm{f}(\mathrm{a}, \mathrm{b})=\sim(\mathrm{a}+\mathrm{b}))$. This system of logical functions can be described as an acyclic graph, in which the vertices correspond to logical functions, and the arcs refer to the arguments of the functions (fig. 1, 2).

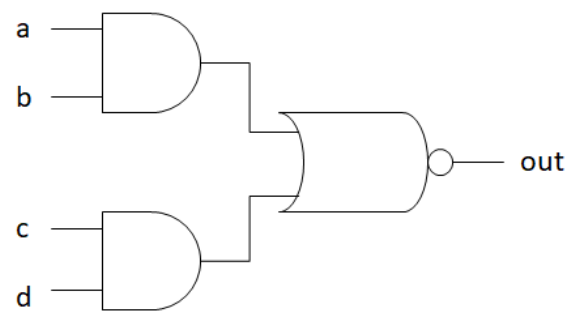

Fig. 1. Description of the AOI22 gate at a logical level

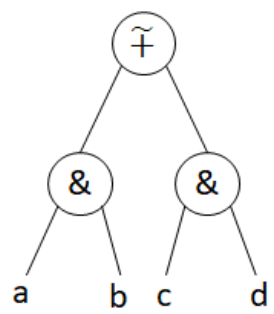

Fig. 2. Graph model of the AOI22 gate

Moreover, despite the fact that logical operations are commutative, the order of the arcs is important. Therefore, the graph is ordered.

The developed algorithm provides a choice of the physical orientation of the transistors. If the direction from left to right corresponds to the direction from the source to the drain, then the transistor is in the normal orientation. If the direction from left to right corresponds to the direction from the drain to the source, then the transistor is in the mirror orientation (fig. 3).

The choice of the layout orientation of the transistors allows to reduce the total area of the circuit by reducing the number of isolating gates [4]. 

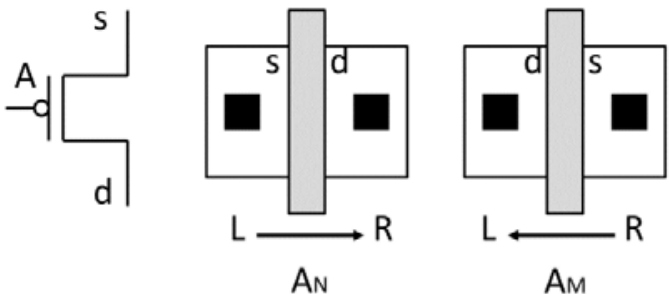

Fig. 3. Transistor orientations (N - normal orientation, $M$ mirror orientation)

\section{ALGORITHM OF STRUCTURAL OPTIMIZATION}

To solve the problem of restructuring circuits, a subgraph comparison algorithm is required. There are two options for solving this problem: logical and structural. Logical (for example, comparison of binary decision diagrams [1]) provides verification of the equivalence of logical functions, but is rather slow, since a check of $n$ ! combinations is required, where $n$ is the number of inputs. The structural approach allows to verify the isomorphism of the circuit's graphs up to permutations. Structural equivalence is sufficient, but not a necessary condition for logical equivalence. The structural approach is faster, but to ensure that structural equivalence is also a necessary condition, there must be no duplicate inputs. We use an algorithm that combines both approaches. Structural comparison is used recursively within a logical comparison in the absence of duplicate inputs.

Logical optimization is based on the laws of Boolean algebra. The method uses the following types of logical transformations:

- De Morgan's transformations (fig. 4) [5];

- decomposition of gate (fig. 5) [6];

- $\quad$ gates merging (fig. 5) [7];

- $\quad$ use of double negation [8].
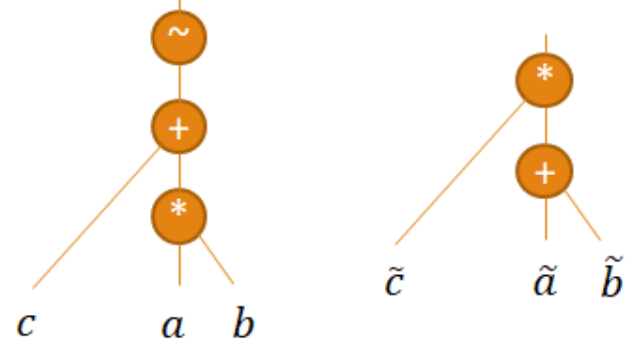

Fig. 4. Replacing the gate with a complementary one

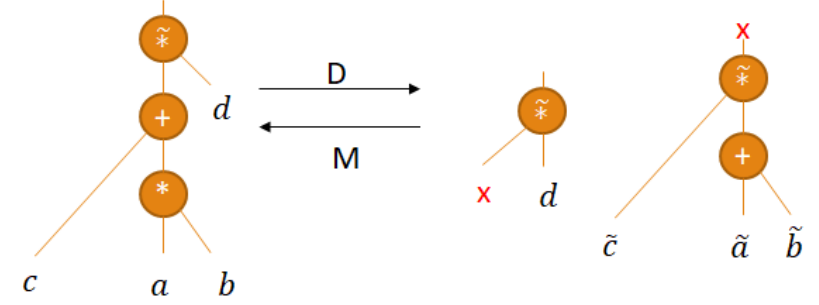

Fig. 5. Decomposition (D) and merging (M)
The following objective function is used in structural optimization:

$$
\begin{aligned}
F_{\text {cost }}(G) & =k_{A} \frac{A}{A_{0}}+\left(1-k_{A}\right) \frac{P}{P_{0}}+k_{\text {Dex }} \frac{D_{e x}}{D_{0}}+ \\
& +k_{D \max } \frac{D_{\max }}{D_{0}}+k_{n L G} N_{n L G},
\end{aligned}
$$

where $\boldsymbol{A}$ is the total area, $\boldsymbol{P}$ is the total power, $\boldsymbol{D}_{\boldsymbol{e x}}$ is the total delay excess for primary outputs, $\boldsymbol{D}_{\max }$ is the maximum delay excess among the primary outputs, $\boldsymbol{N}_{\boldsymbol{n} \boldsymbol{L} \boldsymbol{G}}$ number of non-library elements, $\boldsymbol{A}_{\boldsymbol{0}}$ is the initial area, $\boldsymbol{P}_{\boldsymbol{0}}$ is the initial power, $\boldsymbol{D}_{\boldsymbol{0}}$ is the minimum inverter delay, $\boldsymbol{k}_{\boldsymbol{A}}$, $\boldsymbol{k}_{\text {Dex }}, \boldsymbol{k}_{\text {Dmax }}, \boldsymbol{k}_{\boldsymbol{n} L \boldsymbol{G}}$ - weight coefficients for the constituent parts of the objective function.

The resynthesis algorithm does not consider the circuit entirely, but selects a fragment of the circuit with which optimization will be carried out at this step (this fragment is called a "window"). Next, structural optimization is carried out using a modification of the simulated annealing algorithm. In this implementation, algorithm consists of two stages: steps with infinite temperature and steps with zero temperature. Steps with infinite temperature are completely random and can lead to degradation of the objective function. Zero-temperature steps are greedy, and at this stage only those decisions that improve the value of the objective function are made. At each annealing step, a logical transformation is first selected, then an object for the transformation is selected. After this, a study of the state space of de Morgan transformations takes place.

\section{TRANSISTORS ORIENTATION OPTIMIZATION}

An isolating gate between two adjacent transistors can be removed if two contacts located on opposite sides of the isolating gate are connected to the same node [9]. For example, in fig. 6, two transistors are parallel connected; both transistors are in normal orientation. In this case, it is impossible to remove the isolating gate, since the contacts located on both sides of it are connected to different nodes. But if one of the transistors is reoriented to the mirror one, as it is done in fig. 7 , it will be possible to remove the isolating gate and one of the contacts and get a more compact sketch of the layout (fig. 8).

To obtain optimal result, two methods are implemented. The first is used if the number of inputs in the gate is less than a specified number, and consists in a complete search of all possible options. There will be $n !\left(2^{\wedge} n+2^{\wedge} n\right)$ variants in total, where $n$ is the number of gate inputs, $\mathrm{n}$ ! - the number of possible permutations of transistors, $2^{\wedge} \mathrm{n}$ - the number of possible variants of transistors orientations. In this case, the best solution is provided. But due to the fact that the number of transistors permutations has a factorial dependence on the number of inputs, this method is not suitable for gates with a large number of inputs. In this regard, if the number of inputs exceeds a certain number, then the solution is sought using a heuristic approach, the essence of which is to find two transistors with two contacts connected to one node, and 
put them side by side, turning them into the most suitable orientations.

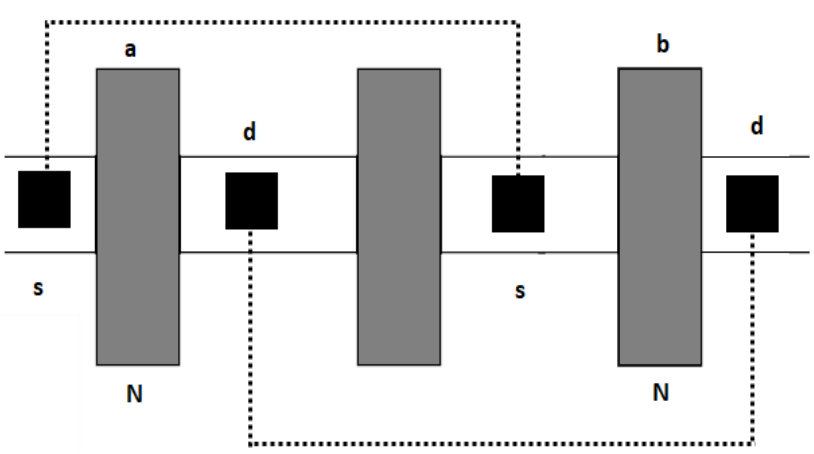

Fig. 6. Transistors are in normal orientation

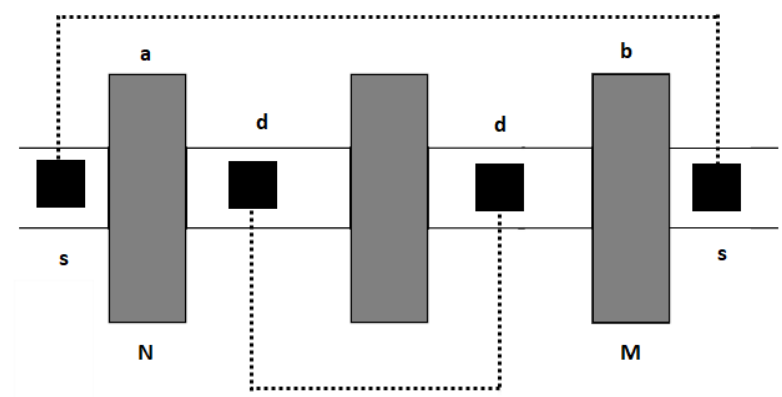

Fig. 7. Transistor $a$ is in normal orientation, transistor $b-$ in mirror

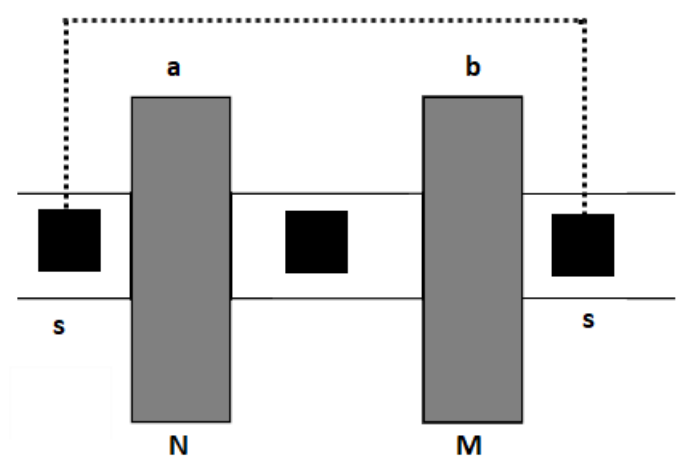

Fig. 8. Removing the isolation gate

\section{DESCRIPTION OF THE DEVELOPED PROGRAM}

The input to the program is the schematic description of the circuit, which is extracted into a logical one. Then a local resynthesis cycle is entered. The next step is a logical resynthesis in the window. After that, the resulting logical description is extracted into a transistor description to select the optimal positions and orientations of the transistors in the gates. Then the new version is compared with the old one. The cycle of local resynthesis continues until all gates are considered. The output of the program is the SPICE description and the Verilog description of the obtained circuit.

The general sequence of actions is shown in fig. 9.

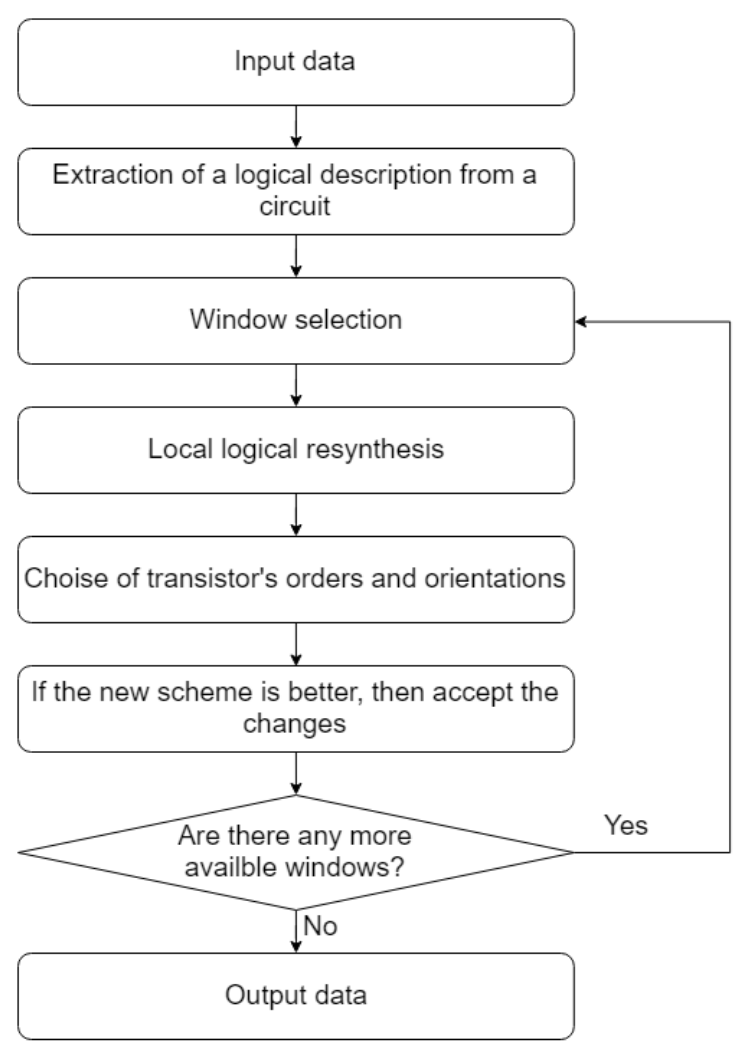

Fig. 9. Block diagram of the developed algorithm

Fig. 10 shows the circuit c17 from the ISCAS 85, which can be transformed by structural optimization into the circuit shown in fig. 11.

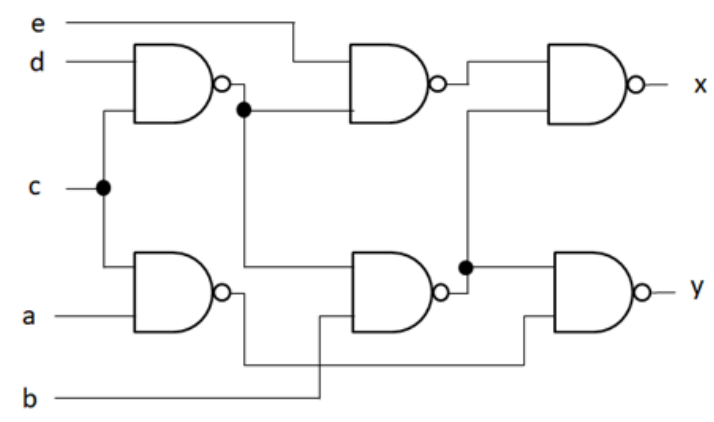

Fig. 10. Circuit c17

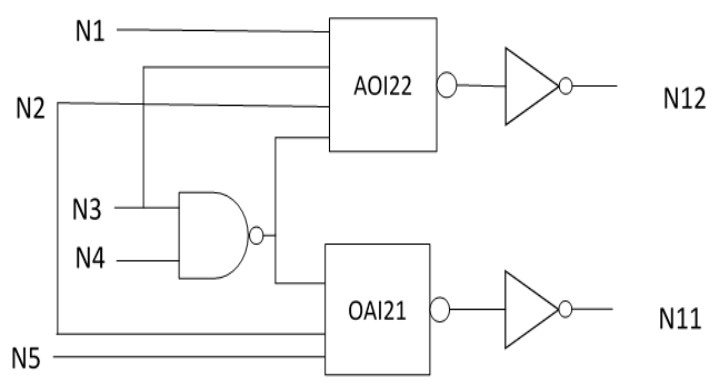

Fig. 11. The circuit obtained as a result of the resynthesis of the $\mathrm{c17}$ circuit 


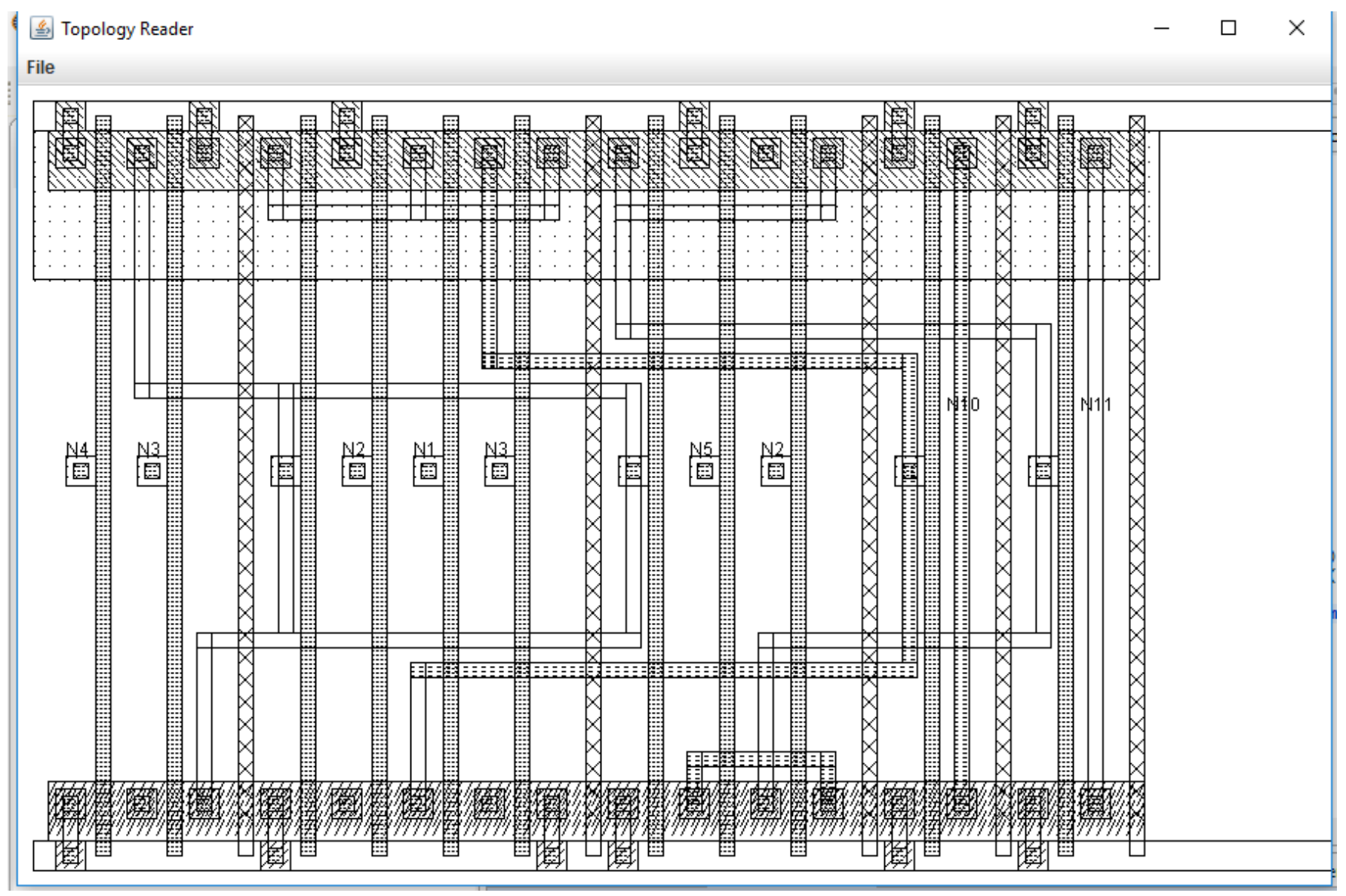

Fig. 12. Sketch of the obtained circuit after optimizing the location and orientation of transistors

The result of layout optimization after resynthesis is presented in the form of a sketch of the layout of the circuit without rendering the input and output buses (fig. 12).

\section{RESULTS}

Numerical experiments confirming the effectiveness of the developed methods and algorithms were carried out using test circuits from standard sets. Testing was conducted in two modes: in the first, structural optimization took place (table 1); in the second, layout optimization was added (table 2).

Table 1

The results of the program

\begin{tabular}{|l|c|c|c|}
\hline Circuit & $\begin{array}{c}\text { Initial } \\
\text { number of } \\
\text { transistors }\end{array}$ & $\begin{array}{c}\text { The number of } \\
\text { transistors after } \\
\text { structural } \\
\text { optimization without } \\
\text { delay control }\end{array}$ & $\begin{array}{c}\text { The number of } \\
\text { transistors after } \\
\text { structural } \\
\text { optimization } \\
\text { with delay } \\
\text { control }\end{array}$ \\
\hline C1355 & 2308 & 1452 & 1570 \\
\hline C1908 & 3482 & 1662 & 1746 \\
\hline Cnt_0 & 352 & 268 & 278 \\
\hline Cnt_1 & 372 & 270 & 316 \\
\hline Cla & 1008 & 720 & 802 \\
\hline C17 & 24 & 22 & 22 \\
\hline
\end{tabular}

\begin{tabular}{|l|c|c|}
\hline Circuit & $\begin{array}{c}\text { Initital number of } \\
\text { isolating gates }\end{array}$ & $\begin{array}{c}\text { Number of gates after } \\
\text { transistors orientation } \\
\text { optimization }\end{array}$ \\
\hline C1355 & 725 & 266 \\
\hline C1908 & 830 & 305 \\
\hline Cnt_0 & 133 & 56 \\
\hline Cnt_1 & 134 & 53 \\
\hline Cla & 359 & 149 \\
\hline C17 & 10 & 4 \\
\hline
\end{tabular}

Structural optimization was carried out twice: for the first time there was no restriction on the percentage of delay degradation, in the second there was a control of exceeding the delay rates. The maximum allowable percentage of degradation delays during optimization is $10 \%$.

Due to structural optimization on large circuits, it is possible to reduce the number of transistors by $30-50 \%$ while controlling the speed. By choosing the order and orientation of the transistors, the result obtained can be improved by an average of another $8 \%$. 


\section{CONCLUSION}

In this paper inter-gate resynthesis algorithm that combines two approaches was proposed.

The first approach is aimed at area minimization by optimizing the logic function. For this purpose a graph model was developed that describes the logical function of the circuit. Due to the boolean form of the graph, it is possible to preserve a sufficient number of degrees of freedom.

The second approach optimizes the layout structure of the scheme. Besides an additional gain in terms of area, this simplifies the automation of the synthesis of layout.

As a result, an algorithm in which these approaches are consistently executed within the optimization cycle was obtained. It has been tested on a set of standard test circuits. In the course of this experiment, results confirming its effectiveness were obtained. Results with and without delay control were obtained. In addition, the algorithm of inter-gate resynthesis has already established itself as efficient and fast in the field of designing blocks and elements on promising FinFET technologies [10].

In the future, it is planned to compare the results of the developed methods and algorithms with the existing analogues in terms of failure resistance parameters and efficiency of the placement of elements in the FPGA basis with a hierarchical architecture.

\section{SUPPORT}

The study was conducted with the support of the Russian Foundation for Basic Research (projects No. 1807-00621 A, 18-07-00626 A).

\section{REFERENCES}

[1] Bryant R.E. Graph-Based Algorithms for Boolean Function Manipulation // IEEE Transactions on Computers. 1986. P. 677-691.

[2] Gavrilov S.V., Gudkova O.N., Schelokov A.N. Logikovremennoj analiz nanometrovyh shem na osnove interval'nogo podhoda (Logic timing nanometer circuits analysis using interval approach) // Izvestiya UFU.
Tehnicheskie nauki 2012. №7 (132). S. 85-91 (In Russian).

[3] Gavrilov S.V., Ivanova G.A., Manukyan A.A. Metody proektirovaniya zakaznyh slozhno-funkcional'nyh blokov v bazise elementov s regulyarnoj topologicheskoj strukturoj v sloyah polikremniya i diffuzii (Design methods for custom complex-functional blocks in the elements basis with a regular layout structure in the polysilicon and diffusion layers)// VI Vserossijskaya nauchno-tehnicheskaya konferenciya «Problemy razrabotki perspektivnyh mikro- i nanoelektronnyh sistem - 2014». Sb. tr. pod obsch. red. akademika RAN A.L. Stempkovskogo. M.: IPPM RAN, 2014. Chast' I. S. 161-166 (In Russian).

[4] Gavrilov S.V., Kareva E.S., Ryzhova D.I. Razrabotka algoritmov logiko-topologicheskogo sinteza bibliotechnyh elementov i blokov s regulyarnoj strukturoj dlya tehnologicheskih norm proektirovaniya $32 \mathrm{~nm}$ (Development of algorithms for the logic-layout synthesis of library elements and blocks with a regular structure for technological design standards $32 \mathrm{~nm}$ ) // Izvestiya VUZov. Elektronika. 2017. T. 22. № 4. S. 369-378 (In Russian).

[5] Uilkinson B. Osnovy proektirovaniya cifrovyh shem (The Essense of Digital Design). Izdatel'skij dom Vil'yams, 2004. 320 s (in Russian).

[6] Gavrilov S.V., Glebov A.L., Pullela S., Moore S., Vijayan G., Dharchoudhury A., Rajendran Panda, Blaauw D. Library-Less Synthesis for Static CMOS Combinational Logic Circuits // Proceedings ICCAD-97. 1997, San Jose, CA. P. 658-662.

[7] Gavrilov S.V., Glebov A.L. BDD-based circuit level structural optimization for digital CMOS // 1-st Intern. Workshop «Multi-Architecture Low Power Design». 1999. P. 45-49.

[8] Turgis S., Azemad N., Auvergne D. Design and Selection of Buffers for Minimum Power-Delay Product // ED\&TC96. P. 224-228.

[9] Gavrilov S.V., Kareva E.S., Ryzhova D.I., Schelokov A.N Metody razrabotki grafovyh modelej regulyarnyh struktur FinFET tranzistorov s nezavisimymi zatvorami (Methods of developing graph models of regular structures of FinFET with independent gates)// Izvestiya UFU. Tehnicheskie nauki. 2017. №7 (192). S. 175-185 (In Russian).

[10] Gavrilov S., Ryzhova D., Vasilyev N. Models and methods of inter-gate resynthesis at the transistor level for nanoelectronic circuits based on FinFETs // 2018 IEEE Conference of Russian Young Researchers in Electrical and Electronic Engineering (EIConRus). 2018. P. 1364-1367. 